\title{
Strategic Frameworks
}

Because any discussion of the strategy of an organisation generally involves reference to various frameworks and specific concepts, here are some that we will use throughout the remainder of this book. As Donald Siegel and Sohvi Leih state in their editorial to the special issue of strategic management for universities, such frameworks are useful as lens through which to identify problems, evaluate various aspects of strategy and judge if it will deliver a sustainable future. ${ }^{1}$ Also, it is this language of the discipline that is largely missing from the published statements of strategy refereed to throughout this book.

\subsection{Business Models}

Business model is a term used by strategists in different ways. Some use it as a framework similar to the value chain in Fig. 7.1 (in Chap. 7) for describing the set of integrated activities for making something and selling it. Other people use the term as a theory of firm value creation, and others use it as a catchphrase about how the organisation works to deliver value to its target customers. For example, as a business theory for Apple, 
the late Steve Jobs held that consumers would pay a premium for ease of use, reliability and elegance in computing and personal digital devices. The best means to deliver these customer benefits was by controlling design, building products with proprietary integrated hardware and software systems, and identifying, branding and controlling complementary products (like iTunes). He once described this as making tools for the mind that advance humankind.

Some companies try to summarise their business model in a catchphrase or by-line. For example, the retailer Costco's business model can be described as 'pile it high and sell it cheap'. The old Amazon business model was 'get big fast and hope that the winner takes all'. The old BHP business model was 'dig and deliver'. The luxury department store Harrods business model is 'rely on the natural instincts of its merchants about taste and style'. Those television shows that feature farmers that grow their own produce and then use this in their own restaurant often describe their business model as 'from paddock to plate'. And some pharmaceutical companies describe their business as 'from bench to bedside'.

Some potential university business models are: education on demand (say, via e-learning technology), workforce education (like the University of Phoenix), discover to educate (which is what MIT claims), from cooks (undergraduates who follow a recipe) to chefs (postgraduates who create new recipes) and the best inputs (school-leavers) create the best outputs (graduates). As snappy as many such descriptions are, they hide the fact that a university has two fundamental business models. One is the creation of new knowledge via research, and the other is the dissemination of old and new knowledge via education. Operationally a university divulges most of the responsibility for both functions to its faculties. This is why every strategy should be clear about the capabilities of these 'business units'. It should also be clear about how the central administration 'parents' the faculties and adds value to their operations. As we note later, the economic roles, resourcing, management and reputations of the portfolio of faculties are key strategic issues. However, seldom does a statement of strategy contain this vital information. 


\subsection{Economies of Scale, Scope and Focus}

In strategy jargon, an organisation can achieve a cost advantage, or in the case of universities, greater efficiency, by better utilising its assets and other resources - economies of scale. For example, a university could better utilise its buildings, IT systems and academics by running courses every day of the year (well maybe not on public holidays). At the old Australian Graduate School of Management (AGSM), while the MBA programme followed the university teaching calendar, executive shortcourses were used to fill in much of the between-term slack periodseven weekends. These courses typically started classes at $8.30 \mathrm{a} . \mathrm{m}$. and concluded at 9 p.m., with breaks for meals and class preparation. The course director was with the students from 7 a.m. (breakfast) to 10 p.m. (evening drinks after class) every day. ${ }^{2}$

A second source of cost efficiency arises because of the ability to spread production and service technologies across products, and leverage intangibles such as a respected brand name-economies of scope or synergies. Consider the AGSM again. The MBA brand name is well known as a particular type of education that is attractive to a particular type of student. Thus, the MBA brand reduces the overall costs of marketing to the targeted full-time, part-time and executive students. The research done to create courses for the MBA programme is also used to create courses for the shorter executive programmes. Many of the case studies used in the MBA programme and the executive short courses were the same. The real-world examples of business practice that were discovered from participants in the executive programmes were later used in the MBA programme to illustrate industry relevance. Research involving data from Australian companies would be published in academic papers and used in both programmes. So the set-up costs of a business topic could be amortised over multiple programmes. Economies of scope are much easier to achieve if there is a commonality of interest, such as in this example of designing a set of integrated courses about general management.

Another source of cost advantage comes from accumulated experience. As individuals and organisations gain experience with a task, they generally become more efficient doing that task. In a university setting we see 
this in the efficiencies of more experienced teachers, researchers and administrators. They make fewer mistakes and they are quicker to get things done. So the mix of experienced and novice staff is important to manage. Few universities seem to acknowledge this source of efficiency. In contrast, in the AGSM there were many more professors and associate professors than in a typical Australian university faculty. There were two reasons for this. One was the efficiency effect just noted. The other was a signal of quality - high-fee-paying students wanted service from experienced academics.

Finally, there is the efficiency gained from economies of focus-the notion of less is more. The AGSM was a graduate school with a limited range of programmes (doctoral programme, full-time and executive $\mathrm{MBA}$, and executive programmes that borrowed from the courses in the MBA). The coursework programmes were targeted at an easily identified group of students - continuing managers, some of whom were supported by the companies they worked for. The total number of students was small by Australian university standards. The school sought academics who had a common interest in business, who could teach and research together and who could teach across different programmes. The school was a highly focused niche operation within the University of New South Wales. From a strategic perspective the AGSM was an example of a unit of the university 'that floated its own boat', a Federal faculty in Fig. 4.4. That is, it was largely self-sufficient and autonomous. Many of the best business schools of the world have this character.

Because it lacked economies of scale, the AGSM strategy was built on economies of scope and focus - the school's resources were utilised more than most of those in a traditional university, and many activities crossfertilised each other more than could be achieved in a typical Australian university. Later in its life the AGSM was merged with the much larger faculty of economics and commerce to become part of the Australian School of Business. Here, the search was for economies of scale.

What is interesting about the statements of strategy of Australia's public universities is the almost complete lack of discussion of anything other than economies of scale through the growth of (international) students. The underlying philosophy here seems to be 'bigger is better' or 'more is more'. However, there are some universities like the California Institute 
of Technology and the London School of Economics, many professional service firms and many businesses that have built great reputations by being focused. So the strategic question arises as to the optimum size and design for a public university in the Australian higher education system, especially one in the major cities where a number of universities co-locate.

Our observation is that a typical Australian university thinks that it needs to be bigger to do more. Our contrarian response is that a university does not need to be bigger to be better. We return to this issue later.

\subsection{Comparative and Competitive Advantage}

Comparative advantages are situation-specific advantages that competitors can replicate at a reasonable cost by relocating or by altering the situational circumstances. That is, they are temporary. For example, some years ago one of Australia's universities decided to advertise at a major sporting event. It was not long until other universities advertised at similar sporting events, such as major rugby union games, golf championships and tennis tournaments. The comparative advantage, if any, of this new advertising campaign was nullified.

Competitive advantages are organisational-specific advantages that cannot be imitated by competitors or can only be mimicked at a very high cost. For example, what universities do better than most commercial organisations is take the time to do research at a higher standard of scientific integrity than these corporations. They employ people with the best training, conflicts of interest are minimal, and the peer-review process helps to ensure that what gets published has been vetted by external peers. This type of slow, deliberate research is their competitive advantage relative to commercial firms. In contrast, the competitive advantage of commercial firms is developmental research where basic research is translated into business process improvements and product and service innovations.

When universities venture into the realm of developmental research, they need to tread carefully. For example, university management systems that focus on academic integrity are often not well suited to getting researches to adhere to the requirements of a commercial environment. Hence, rather than push academics to do more applied research, one 
strategy is to harness the entrepreneurial instincts of some of the students and encourage a new business start-up culture. The role of the academics here is to guide and encourage this cohort. The challenge is to capture some of the rents from the basic research that underpins these new ventures.

A competitive advantage for some Australian universities relative to their peers is their location close to an industrial group or a natural resource or a research hot spot. For example, James Cook University sits beside the Great Barrier Reef, which as a world heritage site provides many research opportunities. Hence, marine science should be, and is, a speciality for the university. In comparison, the University of Newcastle sits beside one of the largest coal mining and exporting regions in the world and a major air-force base (Williamstown), and it is close to one of Australia’s premier wine-growing regions (the Hunter Valley). One might expect that these three locational assets would spur the university to have major programmes that specialise in the research and educational opportunities these locational advantages offer. A look at the university website suggests only small pockets of expertise.

Other competitive advantages are permanent until disrupted by innovations that create a significantly better value proposition for the target customers of the university. For example, the reputations of Oxford and Cambridge Universities encapsulated in their Oxbridge approach to higher education have provided these institutions with an advantage over their local and many overseas universities. So far, this approach to education has withstood many new educational technologies. Also, the alumni networks of these universities provide a substantial advantage in attracting academics, students, benefactors and visitors that further enrich these UK institutions.

Two things are important about comparative and competitive advantages. First, they are defined relative to competitors. Second, they are not necessarily independent or separable. Hence, the total advantage of a university is not simply the sum of its comparative and competitive advantage. It is also important to note that a university can have comparative and competitive disadvantages. For example, the university union-negotiated modest academic salaries and the high cost of living in Australia's big cities have discouraged many overseas star academics from joining an 
Australian university. Also, a poorly functioning admission and registration system can discourage good students from joining a university. ${ }^{3}$

When discussion focuses on comparative and competitive advantage, the next step is to consider sustainable advantage. These are the advantages that management can strengthen, extend into the future and extend across product offerings. They often arise from innovation (a new or different solution to a problem), capacity and cost position (gaining economies of scale), segmentation (a better understanding of student or industry needs) and time (doing things faster). The MOOCs-the Massive Open Online Courses-are an example of this. These courses use innovation, a new knowledge delivery mechanism; segmentation, to reach some traditional and new segments of students; time, to deliver information to students when they want to receive it;and capacity, once a course is established it costs almost nothing for extra students to access it. This is why MOOCs are concerning some universities. Because of their potential disruptive influence on the business model of universities, we will analyse these in the next section.

\subsection{Sustaining Versus Disruptive Innovation}

In 1997 Clayton Christensen, a professor at the Harvard Business School, wrote a book titled The Innovator's Dilemma. This book consists of a set of hand-picked case studies from which he argues that the dilemma organisations face is that by doing the right thing-improving what they are currently doing (sustaining innovation) - they are doing the wrong thing, because they are not seeking to radically innovate and create new markets (disruptive innovation). The first problem with this theory is that it is built on a set of hand-picked anecdotes-a notoriously weak methodology. ${ }^{4} \mathrm{~A}$ second problem is that it largely ignores how the history of an organisation creates a set of enduring commitments to its stakeholders that are very difficult to ignore. Organisations can't expect to prosper by walking away from their current stakeholders or asking them to radically change their behaviour. Notwithstanding these shortcomings, Christensen created a product-line of books (Disrupting Class, ${ }^{5}$ The 
Innovator's Prescription 6 and The Innovative University) and turned this idea into a mini consulting industry.

The third problem here is that Clay Christensen was a master salesperson (and engaging classroom teacher). Many people believed his theory about the importance of disruptive innovation without checking the history of the idea (e.g., Joseph Schumpeter theorised about the 'creative destruction' of businesses in 1942), the solidarity of the foundations on which this thesis was grounded (anecdotes) or the range of the theory (it is both a chronicle of the past [this has happened] and a model of the future [this will keep happening]).

As we noted earlier, academic and management consulting theories are often useful as a lens through which to generate and evaluate strategic options. However, they need to be understood before they are used. For example, two theories underpin the interest in e-learning technologies like MOOCs, and one questions the rate at which these courses are likely to be adopted. These theories are labour productivity, disruptive innovation and the adoption and diffusion of innovations.

\section{Will MOOCs Be Disruptive?}

In the 1960s, William Baumol and William Bowen described the situation where the salaries paid to people rise much faster than the productivity growth of these people. ${ }^{7}$ In areas such as performing arts, nursing, public administration and education this situation is common. In higher education many functions require a similar amount of time to complete as they did 100 years ago, such as designing curriculum and examinations, marking a written essay, assessing a student special case, preparing a lecture, giving this lecture, running a tutorial, supervising a laboratory session. So MOOCs seem to offer a productivity breakthrough. By designing self-service into the course (such as self-paced content access, self-assessment and using social media technologies to get students to engage with each other) some functions can be streamlined, or at least pushed onto the students. Also, once designed and built, these courses are reusable without extra production costs and can be rolled out to vast numbers of students at the same time at minimal extra cost. Thus, the productivity of some aspects of a MOOC course can be increased dramatically. 
Now consider the following prediction made in 2013 from two advocates of disruptive innovation that appeared in the Forbes Leadership Forum.

A revolution is coming to U.S. higher education, one that will sweep away an archaic business model, erase the value of many venerable brands, and enhance the brands of new entrants and nimble incumbents. It will be a tough time for many U.S. colleges and universities but great news for the rest of the world. ${ }^{8}$

Does this dire prediction have any substance?

First, consider school education. The old technologies of books, classrooms and teachers have proved to be resilient to many new 'breakthrough' education technologies. Yes, classrooms are now more intelligent, but they are still recognisable as classrooms. And so are face-to-face lectures, tutorials, laboratory sessions and supervised examinations in universities. There is an intrinsic requirement about these old-style education technologies in the production of a 'university graduate'. And like schools, because a university has a social dimension and is an immersive experience, this requires context, such as human feedback from someone who knows more than the student, immersion time and guided learning.

Second, because MOOCs are an innovation, the theory of the adoption and diffusion of innovations is a useful guide to what is likely to happen. First, what is a MOOC? Richard Lyons, dean of the Hass School of Business at UC Berkeley, suggests that it is more a new distributional channel than a new educational product. ${ }^{9}$ Hence, one benefit resides in receiving a course 'anytime, anywhere'. Subsidiary benefits include reduced travel time, the comfort of working in one's own space and sometimes freemium pricing - the ability to sample a course for free. There are costs, some of which relate to private and network information technology, some to the loss of face-to-face contact in a university environment (inspiration and networking) and some to the inferior learning outcomes that often occur. The learning outcomes may be enhanced when MOOCs evolve to be able to customise content to individual learning styles. So at present on the spectrum of innovations MOOCs sit more comfortably in the middle than the ends, namely as a 'step-change' rather than 'incremental' or 'radical' innovation. This suggests that their 
present disruptive capacity is more limited than the spruikers who are pushing them suggest.

Another reason for the slower than predicted adoption and diffusion of MOOCs is that they are trying to replace the dominant design of university education, much of which is built around face-to-face interaction, and, as we noted earlier, much of which involves living on campus. To illustrate how difficult some dominant designs are to break, consider that most readers of this book are using a QWERTY keyboard on their computer and phone. (It was originally designed to slow down typing speed, not to make it easy!) Also, innovation theory suggests that there will be a lot of trial and error before MOOCs either die or become a 'standard' product form. So, spare a thought for the President of the University of Virginia whose Board of Trustees tried to fire her in 2012 for failing to disruptively innovate with sufficient speed!

Third, it is not yet clear who MOOCs are aimed at. For example, most people who attend university want a certified credential. And most people who employ these graduates want to know that they have reached a reasonable standard of (examination tested) education. Hence, there is a well-developed market for the traditional university-style education, and it is not obvious how MOOCs will replace this time-honoured, immersive approach. So where might they gain traction?

One role for MOOCs is to offer courses for people who want to do small off-site units of university study that will count towards a degree (called micro-credentials). Another group is alumni who want convenient access to life-long or top-up learning. Another group is people who are curious about a topic rather than interested in a formal credential. Many retired people reside in this segment. Finally, there are people in countries with weak higher education systems and shortages of quality educators. Here, the lure of low-cost, high-quality, convenient education is great. If this segmentation persists, the different needs of each group will drive the design of different MOOCs.

So while some MOOCs are getting good numbers of attendees, at present many of these tend to be the fringe dwellers of a traditional university education. They are people who do not want to commit to a full degree or would not be admitted under the normal admissions criteria. Thus, MOOCs seem to be increasing the reach of the type of material 
universities produce rather than cannibalising the traditional student cohort. They seem to be more of a complement to a traditional university experience than a substitute for it.

Fourth, MOOCs are based on a different learning model to that offered by a university. So, if students really want to learn, then the current university model is far better than a MOOC. Some insights about learning from John Loughran, the dean of the faculty of education at Monash University, help to explain this argument. ${ }^{10}$ In the past the model of much university education could be characterised as 'telling with teaching' and 'learning with listening'. YouTube and many MOOCs look a lot like this. However, today good educators use a much better model of learning to construct the university experience. They start with the objective of getting people to be knowledgeable of an area and capable of doing something with this knowledge. This requires - creating a need to know, developing ways to engage the student, drawing out the student's prior knowledge, developing a conceptual understanding of content, practising using the knowledge and building a trusting relationship and safe learning environment. This is best done in an environment with a big dose of face-to-face interaction, lots of reading, thinking, practising and talking with others about self-generated ideas.

Fifth, the spruikers of MOOCs suggest that these courses will be designed by the premier academics in each field. This is a contestable proposition because many of very best scholars do not to want to design and deliver this type of course. Their preference is to teach and work with postgraduates. So while these star professors might help design the content of some MOOCs, hopefully they will be developed and delivered by other people with suitable expertise.

Sixth, there is the tricky question of how much money a university can make from MOOCs. At least enough to cover development and operating costs, and then those associated with the inevitable stumbles that will occur as this educational technology develops. Then if these courses do become established, how will they be priced so as not to cannibalise the profitability of existing courses? The demand for curiosity and life-long learning is probably more price-sensitive and fickle than the demand for a certified degree from a traditional university that can be used to enter or progress through the workforce. 
Our conclusion is that MOOCs and many other EdTech innovations are 'work in progress'. So from a strategic perspective, what might a wellestablished university do? Pankaj Ghemawat suggests that rather than ignore or switch over completely, one option is to straddle both the old and new technologies without many linkages between the two. ${ }^{11}$ This at least signals that the university 'is doing something', whether this is true or not. Another option is to combine both technologies, for example by using MOOCs for fact-based learning and the more traditional methods for discursive learning, or using MOOCs as a part of the university entrance requirements, such as Harvard Business School's Credential of Readiness targeted at potential MBA students.

Another strategic question is how fast should a university move to embrace MOOCs? Like many others, we suggest that they become a 'fast follower' rather than 'disruptive innovator'. Fast followers learn from others' mistakes and can capitalise on the technological innovations of other players. Fast followers in this arena might use the services of groups like OES (Online Education Services), FutureLearn and $2 U$ to help them develop material and navigate this new education space. Also, despite what journalists often report, being a fast follower is a less risky and a more likely route to success.

So since 2013, when the previous dire prediction was made, have these courses destroyed the dominant design of university teaching? Not yet. Have they disrupted the traditional university business model? Not yet. Have many of the early innovators failed? Yes. Are we surprised by the slower than expected impact of these courses on higher education? No. Will they eventually disrupt this long-established model? Probably not, but who knows. As we go to print the COVID-19 pandemic is forcing universities to shift most of their courses online. This exercise may boost the development of MOOCs or if the students think that it is delivering a weaker educational experience it may retard this development. Time will tell.

One potential disruption to the traditional education model of the 'standard' university could be developed in the world of gaming and social media. If the psychologists and neuroscientists who design the persuasive technologies that make interactive games and sites like Facebook and Snapchat so successful are asked to create new e-learning technologies, then they might disrupt the traditional forms of university teaching. ${ }^{12}$ 


\subsection{Rankings: Managing to These Measures}

An important strategic concern of many universities around the world is, how should they respond to the numerous rankings that purportedly measure their quality or more specifically their status? Remember the old saying that

What gets measured, matters.

So, should a university play the status ranking game? And if they do, how should they play? Let's explore the second question first because universities do play the rankings game. Then we will suggest why this is the wrong game to play.

\section{Playing the Ranking Game}

During the era before these rankings were developed, academics looked inward and to each other for the attributes that defined quality, status and reputation. However, from a student point of view, many of these attributes, especially those related to research, were largely irrelevant to the quality of their education and whether this made them 'life-ready' or 'work-ready'. So some enterprising people and media outlets saw an opportunity to develop different measures of quality that were more transparent and useful to the people whose money was underwriting the university system. And without too much thought, the Australian government also bought into this idea. So what emerged was a system that reduced each university to a single number-its rank against its peers!

Simon Marginson and Mark Considine (The Enterprise University) suggest that many Australian universities now seek to advance their own prestige and status as an end in itself. In this game two compulsory rankings for Australia's universities are the Excellence in Research Australia (ERA) and the more recent Engagement and Impact (EI). The ERA is a government-imposed quality assurance system that grades selected areas of each university's research as above or below world standards. It has been run four times. Because it is now no longer used to directly allocate research funding, many universities view it as an expensive form of 
government red tape. One estimate was that the 2018 ranking cost close to $\$ 26$ million to conduct. ${ }^{13}$ However, it did suggest that $90 \%$ of the research submitted for evaluation was at or above world standard. ${ }^{14}$ What it did not reveal was how much research was not presented for evaluation, and by implication, it's less than world-standard quality. The EI assessment reflects a significant change in thinking about the types of research the government values. There must now be a line-of-sight between research and its application or influence outside academic circles.

Three other rankings that are often used define the performance of Australia's major universities are the QS World University Ranking, the Times Higher Education World University Ranking and the Academic Ranking of World Universities (ARWU). While each one uses a different methodology, they all weight research as the most important attribute. For example, the QS World University Ranking measure is composed of the following items:

1. Academic reputation (40\%) - based on a global survey of academics who are asked to identify the leading institutions in their field.

2. Employer reputation (10\%) - based on a survey of graduate employers who are asked to identify the institutions producing the best graduates in their sector.

3. Student-to-faculty ratio (20\%) - a commitment to highquality teaching.

4. Research citations per faculty member (20\%)—reflects the impact of research.

5. Proportion of international faculty (5\%) - to reflect an institution's success in attracting faculty from overseas.

6. Proportion of international students (5\%) — to reflect an institution's success in attracting students from overseas.

What is notable here is that notwithstanding the complexity of a modern university and its multiple aims, the underlying model is very simple and simplistic. The focus is clearly on academics, employers and surrogates for teaching. Nothing else matters-not equity, diversity, social inclusiveness, ethics, values, industry engagement or many of the other factors that populate the public statements of strategy. The other major 
reputation polls are equally focused. So any university that aspires for a strong social equity footprint is not doing this to help win the rankings game. It is doing this to create a separate citizenship reputation.

In general, rankings of the type in which universities seek to excel can be used for six purposes:

- As a signal of unobserved institutional quality, and thus

- as a decision aide for students, staff and donors.

- As an evaluation tool by the university's main bank and regulator-the government.

- As an evaluation tool of the vice chancellor by the university council.

- As a template for change-strategy and/or operations.

- As a vehicle to legitimise bragging rights for the best performers.

In their best light, rankings can motivate value-enhancing competition amongst universities. However, for this to occur they have to be good (valid and reliable) measures of quality. The academic community has conducted a large amount of research that looks at the scientific validity of these measures. Much of it is not very complementary. ${ }^{15}$

In their worst light, rankings can motivate value-decreasing operational decisions. For example, one way to game the rankings is to make sure that the university's reportable workforce (aka the academics who are counted in ranking scheme) are the active researchers. Now consider the following critique by the vice chancellor of one of Australia's best universities.

Some universities are overtly manipulating their reportable workforce, converting, en masse, academics into teaching-only roles that break the link between higher education and research.

Universities defend the segregation of the teaching and research workforces under the seemingly reasonable explanation of comparative advantage: let the best teachers focus on teaching, and let the best researchers focus on research. But in many cases, staff are tapped on the shoulder to take on large teaching loads not based on their teaching ability, but rather their perceived under-performance within research. 
And there are consequences. Many of the next generation of students will be taught entirely by people who are not creating new knowledge through research.

Future students will ask, if I am not being taught by a research-active teacher, why exactly should I get my education at a university at all?

Australian National University (ANU) Vice Chancellor Professor Brian Schmidt, 'A great university is first made by its students.' ANU website (7 November, 2019) ${ }^{16}$

From a strategic perspective the international rankings highlighted on a university's website identify the areas of research where the university should focus. They also indicate who might be considered as key competitors, namely, the other universities who also promote their place in the same ranking.

From a global perspective what these rankings reflect is a 'layering' of universities in terms of (mainly research) quality. As Peter Booth, a past deputy vice chancellor of the University of Technology Sydney, noted, in this layered market most of Australia's universities could be considered as 'middle-tier' ${ }^{17}$ He suggests that they will prosper only if they can identify and execute an appropriate strategy in this tier. In essence, he is suggesting that regardless of how hard they try, most of Australia's public universities will never become elite, global institutions.

A quick analysis of these rankings also uncovers a potential problem for Australia's universities. It is the rise of the Chinese universities, many of which now clearly outrank those in Australia. For example, an article in The Economist newspaper reported that in 2018 Tsinghua and Peking Universities are two of the best in the world. ${ }^{18}$ And when it comes to scientific publications in the STEMM (science, technology, engineering, mathematics, medicine) disciplines, China has 6 universities in the top 15 , while Australia has none. The problem here is that China is a source of a large number of international students. So the question arises that if the top Chinese universities have a better ranking than ours, why are the Chinese students coming to Australia? The answer will be a combination of factors such as education, emersion in a Western society, lifestyle and gaining points for resident status. 


\section{Playing the PR Game}

A public relations problem for Australia's universities that play these rankings games is that when a person searches across the websites of a number of universities, the cherry-picking of rankings to brag about becomes very obvious and very annoying. This weakens any claim made by the university about its relative standing. It also weakens the perceived integrity and probity of the university. Surely model social citizens as our universities aspire to be would not engage in such blatant public relations hype!

\section{Why Rankings Is the Wrong Game to Play}

From a strategic perspective, seeking to better one's place in a statusranking system is a competitor-focused strategy. It is a zero-sum gamefor every winner there is a loser. To beat one's competitors requires understanding the rules of the game which are enshrined in each multiattribute measure, and then doing better on most attributes. Some can be improved by the university's efforts, while some cannot. For example, if an international ranking has an attribute that focuses on graduate employment, then the economic conditions of the country largely determine graduate demand. And if the percentage of international students is important, then currency exchange rates are an important driver of performance here.

When the focus is on beating competitors, it is easy to become complacent about being customer-focused, especially when there is ambiguity about how the ranking metric actually drives customer satisfaction. For example, two of the factors in the QS World University Ranking are the proportion of international faculty and the research citations of the faculty. But how do these requirements make students more life-ready or work-ready? How do they increase student satisfaction with the educational experience?

To highlight the shortcomings of a competitor focus, consider the goal Morita-san (Akio Morita) set for Sony after World War II. He wanted the company to be known for quality. His bigger goal for Sony was to help make Japan known for quality. So Sony was playing a positive-sum game, because as its quality improved, so did Japan's quality, and with it the country's competitiveness. Quality is also a target that moves in the right 
direction because as it improves, customer expectations rise, and to meet these higher expectations, quality needs to improve further. Quality is much more customer-focused and value creating than beating a competitor.

Wouldn't it be nice if Australia's leading universities had the vision of Morita-san and set out to enhance quality and thus the reputation of Australia's universities rather than climb up various greasy ranking polls? We wonder if any Australian university will have the courage to formally disengage from the ranking game.

\subsection{Strategic Reputation Management}

Many universities confuse status and reputation. Status is one's position in a ranking such as those discussed earlier. In contrast, reputation is a broader evaluation of the university's citizenship and competence (in education and research). ${ }^{19}$ So a university has at least three distinct reputations - one each for citizenship, education and research. Because each reputation will be driven by different sets of factors and be more or less relevant to different groups of stakeholders, and because they may or may not be correlated with each other, they need to be measured separately. In Australia some universities commission customised reputation surveys such as the one offered by the Reputation Institute, known as RepTrak ${ }^{\text {тM }}$, in an attempt to unpack these reputations.

Reputation is important because it summarises a university's achievements - we have a world-class reputation for XYZ; it makes a promise about what to expect-we will uphold and enhance this reputation; and it acts as a performance bond to all the university's stakeholders—we will do nothing to damage this reputation. It is strategically important in a competitive market because a good reputation helps to attract students, staff, research funds and donations. It also helps to add gravitas and credibility to its communications and those of its staff. The reputation of a university is arguably its single most important intangible asset. Hence, you would expect that a statement of strategy would contain a clear set of investments and actions for building, maintaining and protecting reputation. 
While the websites and published statements of strategy of many universities note their goal of doing well in various so-called reputation polls, there is seldom any direct mention of their three types of reputation. This is also the case in these institutions' annual reports. So one is left to assume that the implicit strategy is to engage more with industry and society (citizenship reputation), teach better (education reputation) and publish more (research reputation). But 'working harder' is not a corporate strategy or a reputation strategy.

\subsection{Taking Stock}

When we are asked to look at the strategy of an organization, we start by filling in the boxes in the following diagram. It is a bit like doing a stocktake. What does the organisation say are its objectives? What are its current capabilities? What are the key characteristics of the environment in which it competes for resources? Who are the target customers? The answers to these four simple questions should be clear in any strategy document. However, it is the links between them (the arrows in Fig. 5.1) that often reveal some nasty surprises.

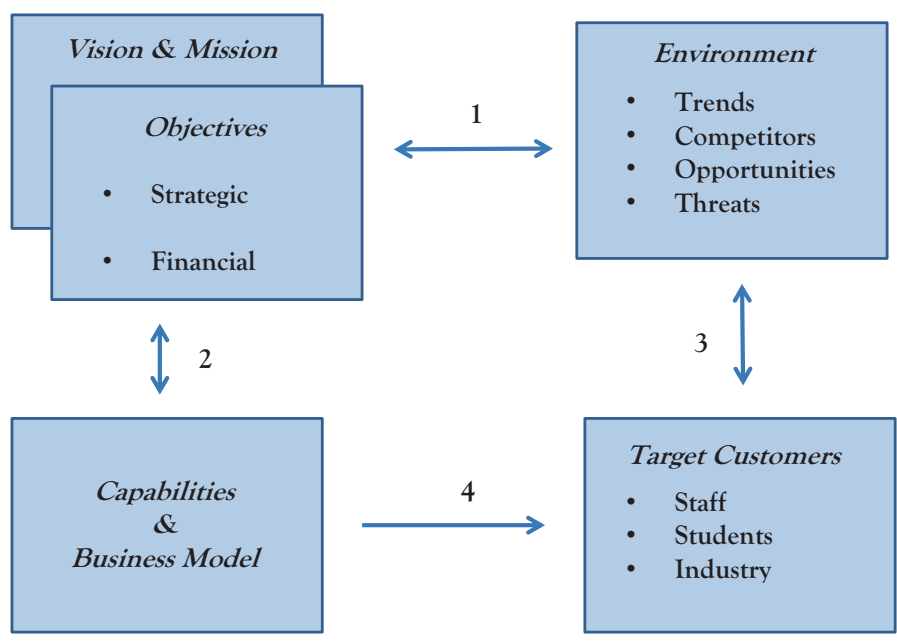

Fig. $\mathbf{5 . 1}$ Taking stock 
Arrow \#1 is a reality check. Sometimes this is called assessing external fit. Given what is happening in the external environment, are the organisation's objectives reasonable? A danger signal flashes when an organisation states its objectives without adequate reference to the conditions in the prevailing environment. This is one of our principal criticisms of Australia's public universities. They simply don't provide a clear snapshot of trends, opportunities, threats and competitors, or what will happen in the future. Hence, one can't determine the strength or weakness of Arrow \#1.

Arrow \#2 is another reality check. This is sometimes called assessing internal fit. Are the institution's capabilities and business model strong enough to meet its objectives? If a university states that it wants to make a global contribution in some form, then it will need some very strong capabilities. If it wants to become the number one teaching or research institution in Australia, then it needs to identify who currently holds this position and what capabilities will allow it to topple the incumbent. A danger signal flashes here when an organisation states an objective and it is not clear what capabilities or business model is needed to deliver it. For example, the Australian National University wants to be Australia's national university, and the University of New South Wales wants to be Australia's global university. But what is a national university, and what exactly is a global or international university; what organisational configuration does it have; what capabilities are needed to deliver these objectives, and how will each university know when it has achieved this status? If answers to these questions are clear and persuasive, then one can have confidence that the universities are onto something importantwell, if stakeholders engage with the objective.

A key aspect of Arrow \#3 is to calibrate the size and nature of demand for the university's products and services. That is, the opportunity to be successful. A good strategy will contain a precise and (data) informed description about what various types of customer (such as students and the organisations that employ them) want, and which ones are to be served (targeted) by the organisation. A poor strategy will refer to the general body of 'students' and 'industry'. The contribution that the discipline of marketing has made beyond that of economics is to model the heterogeneous nature and needs of stakeholders and students. For 
example, in the market for university ideas and services there are subgroups of students with different needs. Typically in statements of strategy universities use a very bland form of segmentation, namely, undergraduate and postgraduate; domestic and international; full-time and part-time. Such bland thinking obscures the needs and wants of the students and hampers developing innovative solutions to their needs. Because this is such an important issue, it deserves a bit more discussion.

There are more insightful segmentation schemes. For example, one is based on whether students are in a formative and developmental or practical and instrumental phase of their life. In the first group the experience of going (full time) to university is like time-released medicine. In the latter group it is like an energy supplement or pain-relief medicine. Another way that these segments can be formed is on the basis of students' views about where the value of their degree lies, such as in the programme (the years spent at university) or the knowledge (which helps to learn a living) or the letters of the degree (which helps to signal some special attributes of the student that will help him or her get a job at their preferred employer). Another way to segment students is by the type of courses they choose. Some have a fairly common global core of knowledge, such as business studies, computing, engineering and mathematics. Others have much local knowledge like teaching, nursing, political science, marine science, tourism and law. And then there is the group of students who go to the only university that offered them a place or the group that favours location and convenience over all other factors. These types of insights will help to understand the attributes of the university and its programmes that affect student choice. They will also suggest where the university should develop its capabilities. In marketing the procedure for doing this is called segmentation, targeting and positioning. ${ }^{20}$

So a good strategy statement will be clear and insightful about which types of students the university wants to attract, how many of these students might be attractive to the institution because it is positioned as a particular type of institution (such as a technology university or an educational university or a research-intensive university) and what types of employers recruit the graduates from various faculties. And for a university to make a major contribution to the workforce, which most of them 
state is a strategic priority, the nature of the derived demand for its graduates also needs to be understood. Questions like these need answers. Which (types of) organisations do and don't recruit from university? Do the same organisations recruit both full-time and part-time graduates? ${ }^{21}$ Do organisations that recruit full-time graduates then put them through some internal training, or do they start work immediately? Where do overseas students get employed-if and when they go home? Answers to these questions hint at the strengths and weaknesses of University X.

Arrow \#4 describes how the capabilities and business model of the organisation will deliver value to the targeted students and staff. It is the strategy of the organisation. A strategy only makes sense in the context of Objectives, Market, and Target Staff and Customers (students and employers). Without all three aspects of this context, the statement of strategy is ambiguous. As noted later, the strategy statements of Australia's public universities pen a lot of words on Mission and Objectives but far too few on the Market and Target Staff, Students and Employers. Hence, they are deficient as credible statements of strategy.

Figure 5.1 doesn't tell whether a strategy is good or not so good, but it does suggest some questions that a council member might ask the vice chancellor about what is proposed. In fact, the role of each framework discussed in this chapter is to provide a source of informed and informative questions about University X's strategy.

\section{Notes}

1. D. Siegel and S. Leih, "Strategic Management Theory and Universities: An Overview of the Special Issue", Strategic Organization, Vol. 16, No. 1 (2018), 6-11.

2. The academics did not mind this because it allowed them to accumulate teaching load in a short span of time and thus free up longer periods for research. Other academics were happy to be paid (at marginal cost to the university) for above-load teaching.

3. P. Nikoletatos, "Shaping sticky students: encouraging lifelong academic relationships in an era of transience", Campus Review (14 June, 2019). 
4. For example, in 2007 Christensen told Business Week that Apple won't succeed with the iPhone. See A. A. King and B. Baatartogtokh, "How Useful Is the Theory of Disruptive Innovation?" MIT Sloan Management Review, Vol. 57, No. 1 (2015), 77-90 for somewhat thorough dismantling of the evidence used in Christensen's theory of disruptive innovation.

5. C. M. Christensen, M. B. Horn and C. W. Johnson, Disrupting Class: How Disruptive Innovation Will Change the Way the World Learns (New York: McGraw-Hill, 2011).

6. C. M. Christensen, J. H. Grossman and J. Hwang, The Innovator's Prescription (New York: McGraw-Hill, 2009).

7. W. J. Baumol and W. G. Bowen, Performing Arts, The Economic Dilemma (Cambridge, Mass.: MIT Press, 1966).

8. B. Guile and D. Teece, "The Real Winners of the Coming Revolution in Higher Education", Forbes Leadership Forum (12 March, 2013).

9. R. K. Lyons, Economics of the Ed Tech Revolution", California Management Review, Vol. 59, No. 4 (2017), 49-55.

10. J. Loughran, "Telling evidence on complexities of teaching", The Australian (12 September, 2018), p. 33.

11. P. Ghemawat, "Strategies for Higher Education in the Digital Age", California Management Review, Vol. 59, No. 4 (2017), 56-78.

12. See for example, H. Edwards, "The Masters of Mind Control”, Time (23 April, 2018), 30-35.

13. T. Dodd, "ERA Winners but process Rankles", The Age (27 March, 2019).

14. This high number doesn't suggest that $90 \%$ of all a university's research is at or above world standard, only that the best research selected for evaluation is at this peer-reviewed level.

15. For example, T. Devinney, G. R. Dowling and N. Perm-Ajchariywong, "The Financial Times Business Schools Ranking: What Quality is this Signal of Quality?” European Management Review, Vol. 5 (2008), 195-208.

16. From http://www.anu.edu.au/news/all-news/a-great-university-is-firstmade-by-its-students

17. P. Booth, "Middle-tier universities in Australia aren't doomed to wither and die", The Conversation (31 July, 2014).

18. "Looking to beat the world", The Economist (17 November, 2018), 33-34.

19. See for example, G. R. Dowling, Winning the Reputation Game (Cambridge: MIT Press, 2016). 
20. G. L. Lilien and A. Rangaswamy, Marketing Engineering (DecisionPro, 2004).

21. For example, at the old Australian Graduate School of Management we found that the organisations that hired full-time MBA graduates were less likely to hire part-time EMBA graduates $(r=-0.7)$. 